\title{
Assessment of the Effect of Neyshabur Green Spatial Configuration on the Temperature of Land Surface and Heat Islands
}

\author{
Elham Jafari, Hadi Soltanifard, Kazem Aliabadi, Hadi Karachi \\ Faculty of Geography and Environmental Science, Hakim Sabzevari University, Sabzevar, Iran \\ Email: Ejafari1392@gmail.com
}

How to cite this paper: Jafari, E., Soltanifard, H., Aliabadi, K. and Karachi, H. (2017) Assessment of the Effect of Neyshabur Green Spatial Configuration on the Temperature of Land Surface and Heat Islands. Open Journal of Ecology, 7, 554-567.

https://doi.org/10.4236/oje.2017.79037

Received: June 28, 2017

Accepted: August 6, 2017

Published: August 9, 2017

Copyright $\odot 2017$ by authors and Scientific Research Publishing Inc. This work is licensed under the Creative Commons Attribution International License (CC BY 4.0).

http://creativecommons.org/licenses/by/4.0/

\begin{abstract}
Urban heat island is a global issue and a consequence of rapid urbanization that leads to higher land surface temperature in urban areas. The range is $0.6^{\circ} \mathrm{C}-1.3^{\circ} \mathrm{C}$ compared to rural and suburban areas. LST (Land surface temperature) is an important parameter in determining the heat island. Understanding the relationship between green space configuration and LST is essential to the effective design of the mechanisms, which reduce the effect of urbanization on UHI (urban heat island). This study examines the correlation between LST and spatial configuration of green space in the urban landscape of Neyshabur city, Iran. Satellite images are obtained from Landsat ETM+ satellite sensor with a spatial resolution of 60 meters in August 2010 and used for the estimation of LST. In order to identify the configuration of green space, five configuration metrics LSI (landscape Shape Index), MPFD (Mean Patch Fractal Dimension), ED (Edge Density), MPS (Mean Patch Size) and MSI (Mean Shape Index) are used. In addition, configuration of the green space and temperature is compared by Pearson's correlation-coefficient. Negative values represent a suppressive/negative effect on each other; the fact that other indicators of spatial configuration are inversely related to temperature means that they weaken the effect of UHI. Results of the study showed that the spatial configuration of the green space notably affects increased LST and UHI. On the other hand, the configuration indicator with the greatest impact on LST was ED, because with increase in margin density further decreases LST.
\end{abstract}

\section{Keywords}

Configuration, Land Surface Temperature, Landscape, Neyshabur, Green Space 


\section{Introduction}

Urbanization is developing at an unpredictable rate around the world [1]. More than half of the earth's residents live in cities, and this figure is constantly increasing [2]. Urbanization rate rose from $17.9 \%$ to $56.1 \%$ from 1978 to 2015 [3], and will reach around 72.9\% [4]. Population in urban areas grew from 746 million to 3.9 billion within a year from 1950 to 2014, which constitute $54 \%$ of the world's population [5].

Expansion of cities is the crucial factor in changing natural landscapes, while it largely influences the structure, function and dynamics of ecological systems as well [6]. Today, environmental issues have become a major concern in the areas without ecological value inside the cities; for instance, declined groundwater level due to the lack water infiltration capacity, soil pollution and growth of non-indigenous plants in the urban environment.

One of the significant outcomes of rapid urbanization is the urban heat island (UHI) effect, which leads to higher land surface temperature (LST) in urban areas. The range of temperature is between $0.6^{\circ} \mathrm{C}$ to $1.3^{\circ} \mathrm{C}$ compared to rural and urban areas [7] [8] [9] [10] [11] which is the result of land cover change. UHI is mainly caused by the change in land surfaces for purposes of urban development [11], in which the used materials are able to save short wavelengths [12] [13]. Consequently, LST increases due to UHI. Impervious surfaces and built structures in urban areas change the local climate through UHIs, and the effects leads to large-scale consequences [14] [15].

Urban open spaces (green spaces) consists of different parts, including parks, gardens, urban forests, natural reservoirs, freeway corridors, playgrounds and other private green areas [16]. Urban green space can alleviate the UHI effect by preventing the entry of the warming sun rays around buildings, air cooling of surfaces and evapotranspiration and lowering the wind speed [17]. Furthermore, the urban green space and vegetation cover play a pivotal role in balancing biophysical human communications and conservation of the urban environment. Green space is the fundamental requirement of any city, which greatly contributes to geology and ecology and enhances urban residents' quality of life [18] [19].

Urbanization changes the urban green space which could lead to the loss and fragmentation of green space, thereby lowering its efficiency [20].

Spatial characteristics and configuration of green space spots in the urban environment have certain effects on UHI [13]. Composition of the landscape directly involves the LST by affecting surface physical characteristics, such as humidity and albedo [21]. Moreover, the spatial distribution of landscape plays a key role in determining the LST due to its impact on the radiation flow and energy flow, which leads to the creation of heat islands [22].

Based on the ecology of the landscape, spatial pattern is a critical determinant of ecological processes [23]. Patterns of the urban vegetation cover in a landscape may potentially affect the LST since spatial arrangement can affect the flow 
of materials and energy in the vegetation cover [24] [25]. Therefore, understanding the effects of landscape pattern on the UHI is essential to ecological improvement and sustainment of the cities [1].

Ecology of the landscape involves the assessment of spatial configuration, for which metrics have been developed to identify the quality of spatial qualities in the land cover spots, as well as their associations with each other [1]. Most of the studies conducted during the past two decades have focused on the association between the composition of green space and LST. Although the correlations between these studies vary, they have reported a negative relationship between the amount of vegetation cover and LST. In unison, the spatial features and configuration of the vegetation cover influence the distribution of UHI inside urban environments [13]. In this regard, some studies consider the size and shape of the vegetation cover spots as a significant determinant of the urban LST. For instance, Zhang et al. (2009) [26] used the Landsat +ETM satellite sensors to obtain the urban LST of Nanjing in China, expressing that the spatial features and configuration of the vegetation cover spots inside cities alter the effects of LST distribution.

In another research, Cao et al. (2010) [27] analyzed ASTER data to examine the spaces of Nagoya Park in Japan. In the mentioned study, the PCI values of 92 parks were collected, and LST was generated. By determining the correlations, the results showed that the shape of the parks affected LST, while a non-linear relationship was observed as well.

According to Weng et al. (2008) [28], there is a relationship between the LST of residential areas and spatial configuration, as the residential polygons with a more complex margin changed LST. Furthermore, Li et al. (2012) [1] studied the urban area of Beijing (China), stating that the concentration of vegetation spots led to higher LST, while the size of green areas had no effect, and the spatial configuration exerted a significant effect on the variability of LST. Maimaitiyiming et al. (2014) [13] inspected the patterns of green spaces and their impact on the LST of Akasa City in the northwest of China using TM-sensor satellite images. In addition, composition and spatial distribution of the green areas were determined based on the percentage of land cover (PLAND). By verifying the relationship between LST and spatial pattern of green spaces, variations of LST were also examined. According to the findings, PLAND was a significant predictor of the LST. On the other hand, spatial distribution of the green spaces influenced LST, and the association of LST and vegetation cover was identified.

\section{The Study Area}

Neyshabur is one of the cities of Khorasan Razavi Province, Iran. This city is located between latitudes $35^{\circ} 36^{\prime} \mathrm{N}$ and $36^{\circ} 52^{\prime} \mathrm{N}$ and between longitudes $58^{\circ} 8^{\prime} \mathrm{E}$ and $59^{\circ} 15^{\prime} \mathrm{E}$ Figure 1 . The area of this city is 8924 square kilometers, 5500 square kilometers of which are plains and 3425 square kilometers are highlands. Slope of the Neyshabur plain is east-westward, while a large part of the plain (particu- 


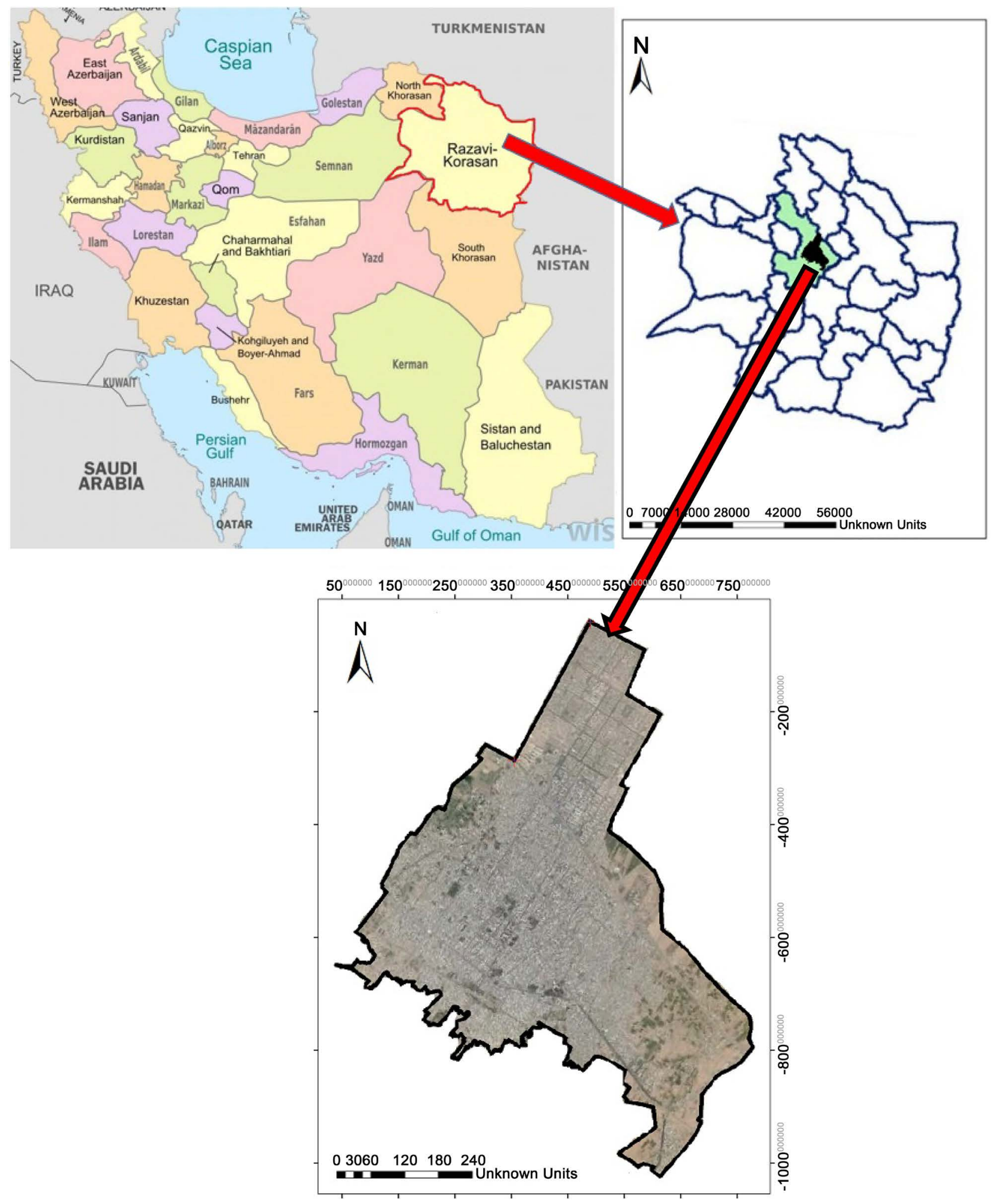

Figure 1. The study area Neyshabur, Iran.

larly the northern part) has a slope with a north-southward direction [29]. Neyshabur is one of the most important cities of Iran in terms of the population, cultural background, tourism, and industrial and historical centers in the north 
east of the country. Moreover, it is a grand symbol of the Iranian history and culture. According to the latest statistics, population of Neyshabur is 276,089, and according to the census of 2011, the population of this city was 433,105 [30].

Neyshabur city has an average temperature of $13.9^{\circ} \mathrm{C}, 100$ days of frost per year, average minimum temperature of $12.37^{\circ} \mathrm{C}$, and average maximum temperature of $39.97^{\circ} \mathrm{C}$ [29]. Total mean of the annual rainfall in Neyshabur city (23 years) is 238.2 millimeters [31], with the maximum monthly mean rainfall of 50.87 millimeters in March, and minimum monthly mean rainfall of 0.16 millimeters in August.

\section{Methods}

By visiting the www.USGS.gov website, satellite images of Neyshabur city in August 2014 were collected from ETM+ sensor of Landsat satellite, with the spatial resolution of 60 meters. Images were used for the quantitative and qualitative examination of the urban green spaces using the ArcGIS 10 software. For the quantitative evaluation of the vegetation cover features, we surveyed factors such as the green space variations, associations of the landscape structures, ecological functions, and landscape metrics. In addition, the ENVI 4.7 software was used for processing the satellite images and determining LST, Patch analyst software was used for calculating the metrics, and the ArcGIS software 10 was used for drawing and analyzing the final maps. Finally, the correlation rate of the landscape metrics and LST was recorded.

The parametric method of Pearson's correlation-coefficient was used at 95\% confidence level to study the correlations between metrics and UHI and assess the changes, which also determined the associations between the metrics of landscape and LST.

Pearson's correlation-coefficient was used to calculate the association between two distance and relative variables with normal distribution. This coefficient has been marked by $r$, and the changes in values were within the range of -1 and +1 , with the symbol indicating the direction of this association. If the obtained value is positive, it means that the changes of two variables occur in the same direction. In other words, by increasing one variable, the other variable increases and the other way around. If $r$ is negative, it means that the two variables act in opposite directions. In other words, the increased value of one variable decreases the values of other variables and the other way around. If the obtained value is zero, it indicates that there is no association between two variables, and if it is +1 , the association is positive and complete. If it is -1 , the correlation is negative and complete.

In this study, Pearson's correlation-coefficient was used for quantitative variables [32] [33].

$$
r=\frac{\sum_{i=1}^{n}\left(X_{i}-\bar{X}\right)\left(Y_{i}-\bar{Y}\right)}{\sqrt{\sum_{i=1}^{n}\left(X_{i}-\bar{X}\right)^{2}} \sum_{i=1}^{n}\left(Y_{i}-\bar{Y}\right)^{2}}
$$


where $Y$ is metric, denotes the mean of the metric, represents LST, is the mean temperature of LST, and $\mathrm{n}$ is the number of each metric.

\subsection{Metrics Selection}

LST and UHI can be linked to the types of land use/land cover (LCLU) [17] [34] [35] while there is also a relationship between the spatial structures of thermal urban patterns and features of the city [17] [36]. Within the past few decades, a large number of landscape metrics have been developed widely used to determine the patterns of landscapes and their correlation with environmental processes [27] [37] [38] [39]. Common metrics of the landscape are selected to express the association between LST and spatial patterns of green spaces. It is also noteworthy that these metrics are often chosen in accordance with four principles [40] [41] [42] [43]: 1) their theoretical and practical significance, 2) convenience of calculation, 3) interpretation and 4) minimum frequency [13]. Following metrics were used in order to study green spatial configuration of Neyshabur urban Table 1.

Table 1. Studied metrics of spatial configuration [44].

\begin{tabular}{cccc}
\hline & & \multicolumn{2}{c}{ Studied metrics } \\
\cline { 2 - 3 } & Metric & Definition & Ranges \\
\hline 1 & LSI & Measures the complexity of the spot's shape. & LSI $\geq 1$ \\
2 & MPS & Calculates the mean spot size in one category of spots & MPS $>0$ \\
3 & MPFD & Measures the mean fractal dimension of the spot. & $1 \leq$ MPFD $\leq 2$ \\
4 & ED & Margin Congestion & ED $>0$ \\
5 & MSI & Mean Form Index Normalized by Area & MSI $\geq 1$ \\
\hline
\end{tabular}

\subsection{Calculating the Surface Temperature}

Measurement of LST was based on the sixth ETM+ band of the Landsat satellite images from August 2010. The Landsat obtained the LST and stored it as a digital number $(\mathrm{DN})$ between 0 - 225. Since the DN values had no physical meaning, they were converted into their reflectance values, so that the DNs could be interpreted in terms of temperature in Kelvin, Celsius or Fahrenheit. The extraction procedures of the temperature are as follows:

a) Converting the DNs into their Reflectance Values:

Converting the DNs into spectral radiation according to the referential values of spectral radiation was based on the following formula:

$$
L_{\lambda}=\left(\text { Gain } * Q_{D N}\right)+\text { Bais }
$$

The bias and gain values were obtained to estimate the reflectance values, which were calculated based on the sixth band. The following formulas show the methods used for the estimation of bias and gain values.

$$
\text { Bais }=\text { LMIN }
$$




$$
\text { Gain }=\frac{(\text { LMAX }- \text { LMIN })}{(\text { QCALMAX }- \text { QCALMIN })}
$$

In the formula above, QCALMAX is the largest DN value (=255), QCALMIN is the smallest DN (=1), LMIN is the spectral radiation value of the DN in the sixth band (=zero), and LMAX is the spectral radiation value of the DN in the sixth band (=25). Additionally, the following formula was used for the conversion of the DN into radiation:

$$
\begin{gathered}
P=G\left(P_{D N}\right)+B \\
P_{R}=\text { Pixel radiance value } \\
P_{D N}=\text { Pixcel digital number } \\
B=\text { Bias (Offset) } \\
G=\text { Gain }
\end{gathered}
$$

b) Converting the Reflectance Value into Kelvin:

$$
\begin{gathered}
T_{K}=\frac{K_{2}}{\ln \left(\frac{K_{1}}{P_{R}}+1\right)} \\
T_{K}=\text { Temperature in degree Kelvin } \\
P_{R}=\text { Pixcel radiance value } \\
K_{1}=607.76 \\
K_{2}=1260.56
\end{gathered}
$$

In this study, $K_{1}$ and $K_{2}$ were different values for TM and ETM+, as well as the fixed calibration coefficient. Kelvin temperature was converted into Celsius using the following formula:

$$
T\left({ }^{\circ} \mathrm{C}\right)=T(K)-273.15
$$

Land surface temperature (LST) and Greenspace Neyshabur was shown Figure 2. LST value was estimated within the range of $22.42-31.99$, with the highest value relating to the north of the city, where there are multiple buildings and few green spaces. In addition, the temperature of the areas without vegetation cover is significantly higher, whereas it is lower in the areas ornamented with green spaces.

Based on the green space map in the current research, it could be inferred that the shortage of vegetation covers in the north of Neyshabur city (e.g., parks) may lead to the congestion of UHI. On the other hand, the lowest congestion of UHI in the western part of Neyshabur could be attributed to the small number of barren lands and industrial zones, as well as the large number of agricultural lands.

\section{Finding}

In this study, five metrics were selected to determine the configuration of green 

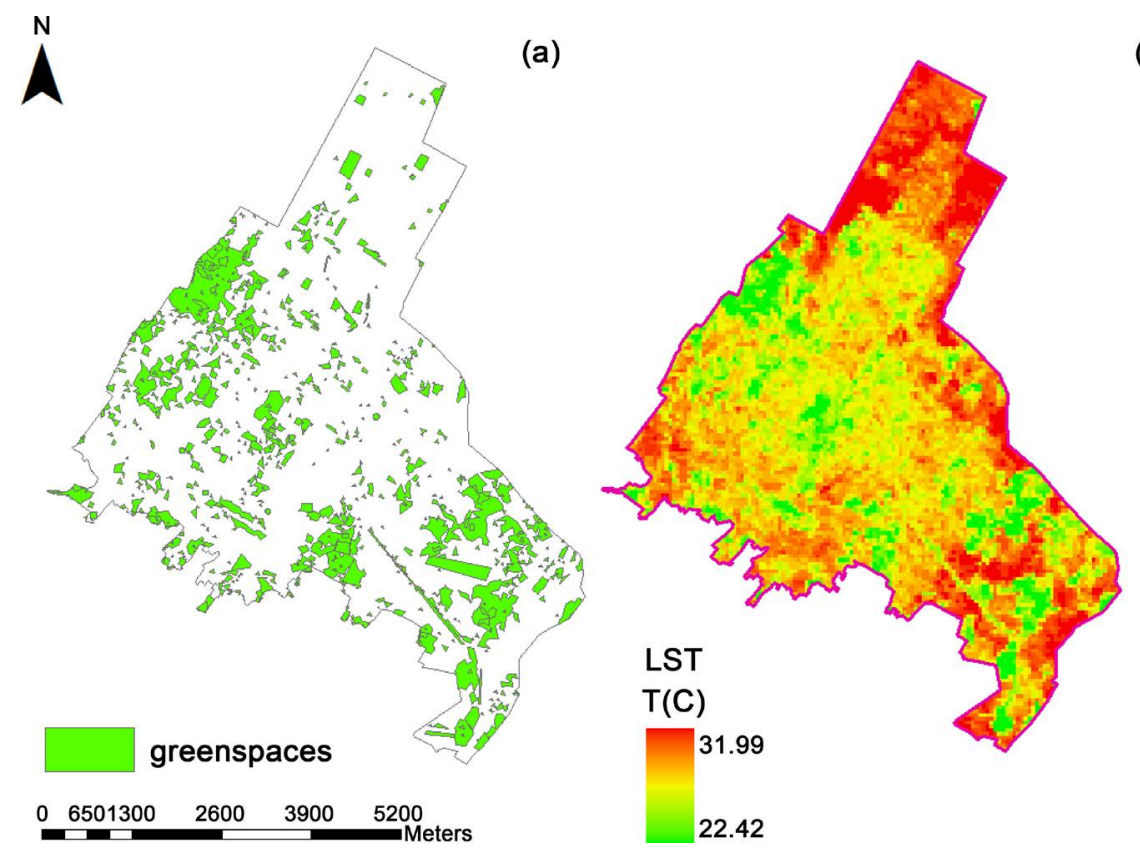

(b)

Figure 2. Land surface temperature (LST) \& greenspace.

spaces Table 1, which also analyzed the relationship between the patterns and LST Figure 3. Initially, we analyzed the changes in landscape metrics using the diagram and linear regression. Afterwards, Pearson's correlation-coefficient was calculated to assess the associations between each metric and LST. Based on the Pearson's correlation-coefficient, there was a significant association between LST and the metrics of the landscape.

Changes of LST during Hexagonal Transects were shown in Figure 4. The correlation-coefficient between the metrics and LST was measured, and the results are presented in Table 2.

The correlation-coefficient between the LST and MPS was estimated at -0.760 . Negative association of the LST and MPS indicated that by increasing MPS, the LST decreases; as such, it could be stated that by augmenting the size of green spaces, ecological conditions improve and LST declines.

The correlation between MSI and LST indices was determined at $r=-0.807$, which indicated the complex shape of the spot, by the increase of which the spot size augments as well. This negative association indicates that increasing the MSI or enlarging the spot leads to the reduction of LST. By decreasing the MSI, LST increases, and consequently, there is the possibility of creating UHIs.

According to the results of this study, the correlation of LST and MPFD was estimated at $r=-0.779$, which shows the complexity of the spot's shape. If this value increases, the spot becomes larger. Negative association of LST and MPFD suggested that by increasing the latter, the LST value decreases.

In the present study, LST and LSI indices were observed to have a significant association, estimated at $r=-0.737$, which involved the shape of the spot. Negative association of LSI and LST suggested that by decreasing the LSI, LST increases. On the other hand, increased value of LSI resulted in a more regular 


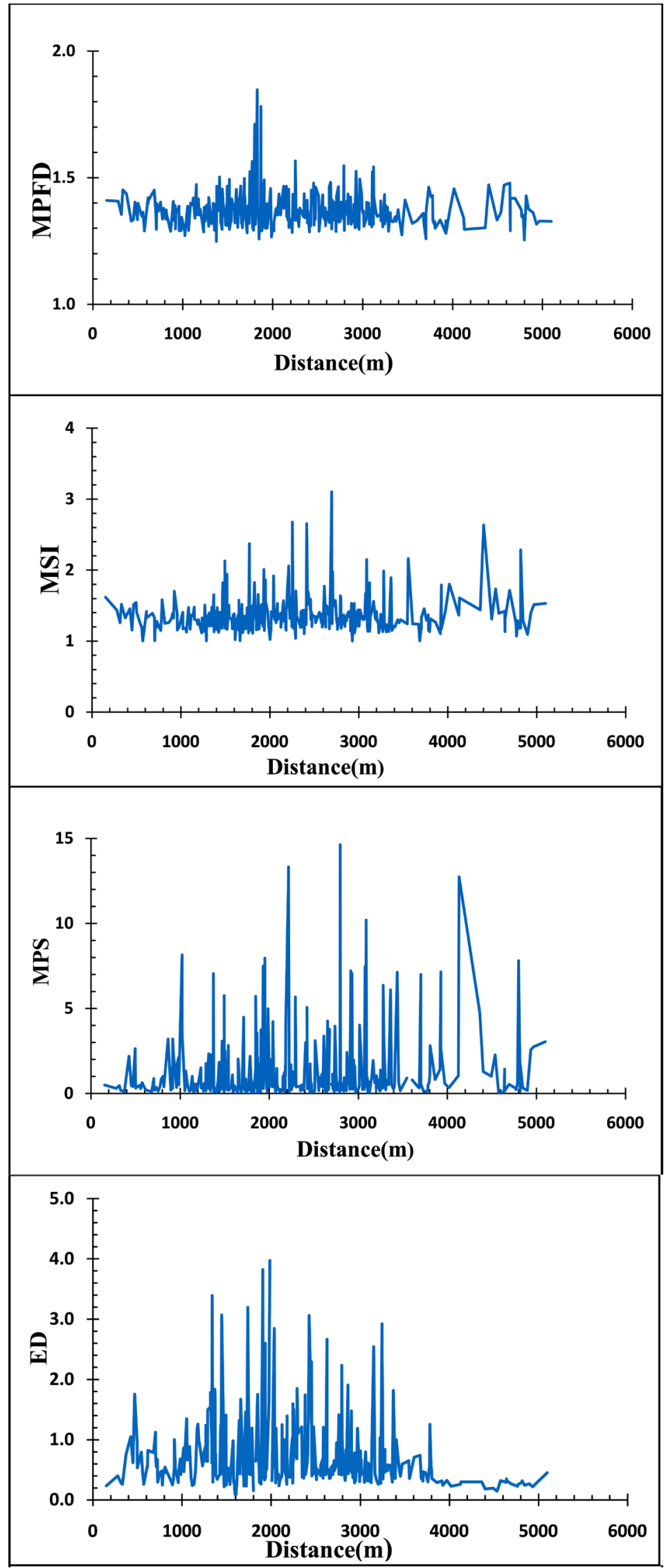




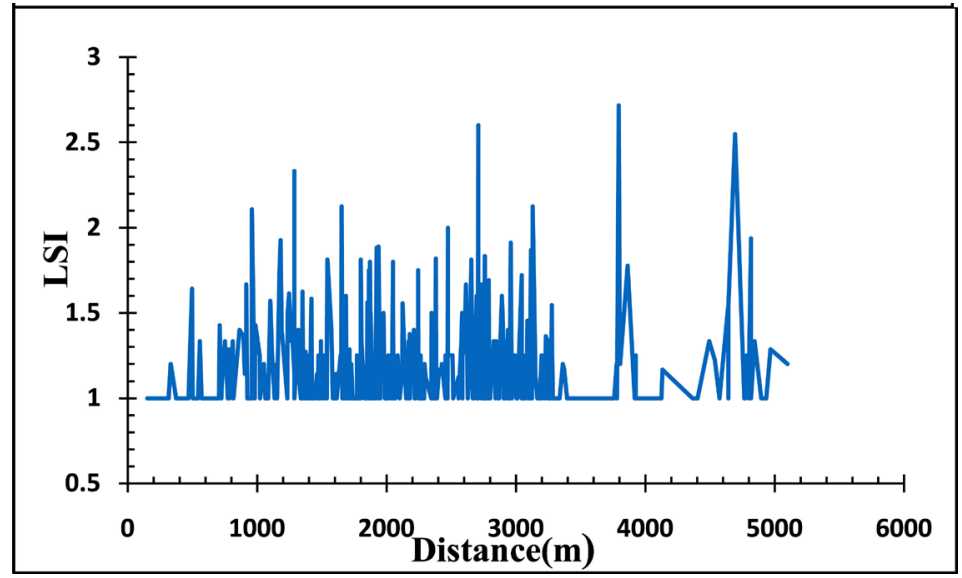

Figure 3. Diagrams of metric changes in spatial configuration.

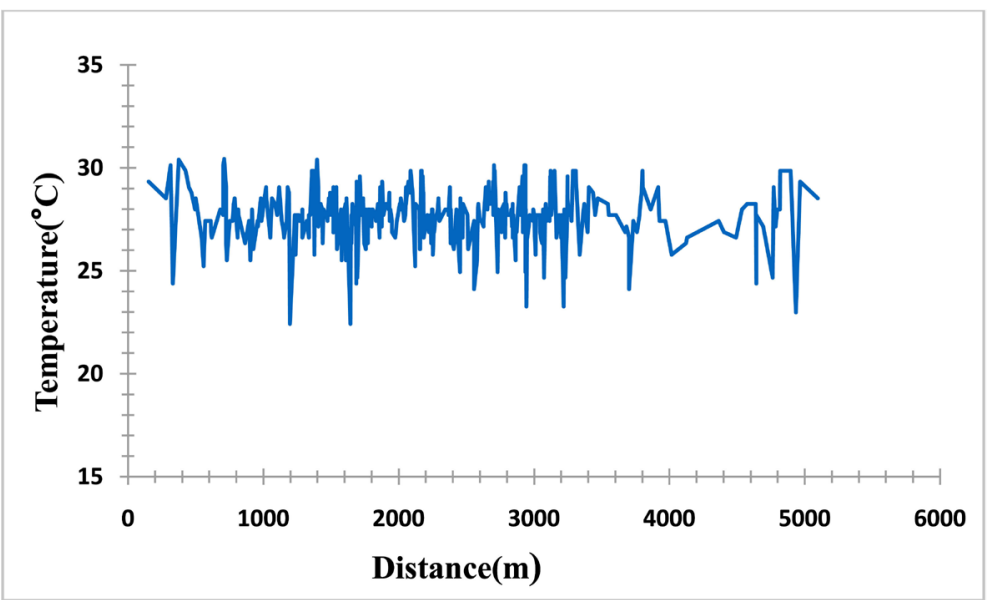

Figure 4. Changes of LST during hexagonal transects.

Table 2. Calculated Pearson's correlation-coefficients.

\begin{tabular}{cccccc}
\hline & \multicolumn{5}{c}{ Metric } \\
\cline { 2 - 6 } & MPS & MSI & MPFD & ED & LSI \\
\hline LST & -0.760 & -0.807 & -0.799 & -0.827 & -0.737 \\
\hline
\end{tabular}

$\mathrm{P}($ value $)=0$

landscape shape, adjustment of its conditions, improvement of ecological conditions, and reduction of LST and UHI.

Ample evidence suggests that green spaces can diminish the effect of UHIs. On a small scale, this temperature reduction occurs in two ways: 1) by using the solar energy and photosynthesis in the metabolism of green covers and 2) through evapotranspiration (cooling evaporation) of the leaf surface. Therefore, green components could diffuse the effect of UHIs on a small scale by using the LST and low temperature of the cooler.

Configuration of green spaces remarkably influences the LST, and the relatively regular green space value can increase or decrease LST effectively. Spatial configuration may have an impact on LST by the flow of energy or energy ex- 
change between varieties of green spaces [23]. Furthermore, spatial configuration of green spaces significantly affects the magnitude of LST. It is also noteworthy that the significance and effect of the spatial configuration indices regarding LST widely vary between different types of green spaces. For instance, $\mathrm{ED}$ is an important configuration index to affect the LST.

Increased margin congestion in various types of green spaces and vegetation covers clearly diminishes the effect of LST. Moreover, the effect of LST decreases by increasing the complexity of the shape of green spaces and vegetation covers. On the other hand, expansion of the complexity of the spot's shape and margin congestion in green spaces may decline by the increased LST shadow. Also, increased margin congestion and complexity of the shape may facilitate the energy exchange between different types of green spaces by improving the interactions between building areas and green spaces, thereby reducing the mean LST.

LST divides the class environment of the spots into the minimum environment of the same class to measure the complexity of the spot's shape, with a value equal or more than one, without any specific dimension. In other words, increasing the area or dispersion of green spots in impermeable surfaces may decrease the mean value of LST in the overall landscape.

By definition [44], a one-unit increase in the natural logarithm of LSI leads to the reduction of mean LST by 1.058 in the landscape. In addition, increased number and size of the spots diminish LST, thereby alleviating the effect of UHI.

\section{Conclusions}

$\mathrm{UHI}$ is one of the important outcomes of urbanization, which occurs due to the changes in the land cover. Understanding the relationship between the configuration of green spaces and UHI for the proper design of mechanisms to reduce the adverse impacts of urbanization on UHI is essential. The present study aimed to examine the correlation between LST and configuration of green spaces in the landscape of Neyshabur city, Iran. In order to compare the spatial configuration, green space and temperature, Pearson's correlation-coefficient was used. Obtained negative values were indicative of the suppressive or adverse effects of each parameter. In addition, it was observed that the indices of spatial configuration are inversely correlated with temperature and UHI, which means that they weaken the effect of UHI.

According to our findings, spatial configuration of green spaces can remarkably affect the magnitude of LST, thereby influencing the creation of UHIs. In this regard, increasing the margin congestion, size of the spots and complexity of the spots' shape in green spaces leads to the reduction of UHI effect. In the present study, the UHI effect was determined by the metrics of landscape configuration and presented by diagrams and correlation-coefficient values.

\section{Acknowledgements}

The authors appreciate the sponsorship of the Ministry of Science, Research and 
Technology of Iran and financial supports of the Hakim Sabzevari University.

\section{References}

[1] Li, J., Song, C., Cao, L., Zhu, F., Meng, X. and Wu, J.G.(2011) Impacts of Landscape Structure on Surface Urban Heat Islands: A Case Study of Shanghai, China. Remote Sensing of Environment, 115, 3249-3263. https://doi.org/10.1016/j.rse.2011.07.008

[2] Lange, E., Hehl-Lange, S.J. and Brewerb, M. (2008) Scenario-Visualization for the Assessment of Perceived Green Space Qualities at the Urban-Rural Fringe. Journal of Environmental Management, 89, 245-256. https://doi.org/10.1016/j.jenvman.2007.01.061

[3] Wang, M. (2016) The Development Process and the Problem of Urbanization in China. Legality Vision, No. 12, 296.

[4] He, W., Huang, Y., Dong, X., Yan, X. and Li, D. (2016) Study on Landscape Pattern Based on Landsat- 8 in the Center of Chengdu City, China. Journal of Environmental Protection, No. 7, 1050-1056. https://doi.org/10.4236/jep.2016.77093

[5] Cen, X., Wu, C.F., Xing, X.S., Fand, M., Garang, Z.M. and Wu, Y.Z. (2015) Coupling Intensive Land Use and Landscape Ecological Security for Urban Sustainability: An Integrated Socioeconomic Data and Spatial Metrics Analysis in Hangzhou City. Sustainability, No. 7, 1459-1482. https://doi.org/10.3390/su7021459

[6] Wang, Y., Li, J., Fan, Z. and Wang, X. (2008) GIS-Based Urban Mosaic and Its Gradient Analysis. IEEE, the Second International Conference on Bioinformatics and Biomedical Engineering (ICBBE 2008), Shanghai, 16-18 May 2008, 4310-4313. https://doi.org/10.1109/ICBBE.2008.577

[7] Aboutaleb, K., Ngie, A., Darwish, A., Ahmed, M., Arafat, S. and Ahmed, F. (2015) Assessment of Urban Heat Island Using Remotely Sensed Imagery over Greater Cairo, Egypt. Advances in Remote Sensing, No. 4, 35-47. https://doi.org/10.4236/ars.2015.41004

[8] Kimuku, C.W. and Ngigi, M. (2017) Study of Urban Heat Island Trends to Aid in Urban Planning in Nakuru County-Kenya. Journal of Geographic Information System, No. 9, 309-325. https://doi.org/10.4236/jgis.2017.93019

[9] Yuan, F. and Bauer, M.E. (2006) Comparison of Impervious Surface Area and Normalized Difference Vegetation Index as Indicators of Surface Urban Heat Island Effects in Landsat Imagery. Remote Sensing of Environment, 106, 375-386. https://doi.org/10.1016/j.rse.2006.09.003

[10] Cook, E., Vanlier, A. and Hubert, N. (1994) Beating the Heat: Mitigating Thermal Impacts. Nonpoint Source News-Notes. Landscape Planning \& Ecological Networks, Elsevier Pub EPA, Amsterdam, No. 72, 72.

[11] Gluch, R.Q.D. (2009) A Muilti-Scale Approach to Urban Thermal Analysis. Remote Sensing of Environment, 104, 123-132. https://doi.org/10.1016/j.rse.2006.01.025

[12] Gartland, L. (2008) Heat Islands Understanding and Mitigating Heat in Urban Areas in the UK and USA in 2008. Earthscan, London.

[13] Maimaitiyiming, M., Ghulam, A., Tiyip, T., Pla, F., Latorre-Carmona, P., Halik, Ü. and CaeTano, S. (2014) Effects of Green Space Spatial Pattern on Land Surface Temperature: Implications for Sustainable Urban Planning and Climate Change Adaptation. ISPRS Journal of Photogrammetry and Remote Sensing, 89, 59-66. https://doi.org/10.1016/j.isprsjprs.2013.12.010

[14] Senanayake, I.P., Welivitiya, W.D.D.P. and Nadeeka, P.M. (2013) Remote Sensing Based Analysis of Urban Heat Islands with Vegetation Cover in Colombo City, Sri 
Lanka Using Landsat-7 ETM+ Data. Urban Climate, 5, 19-35.

www.elsevier.com/locate/uclim https://doi.org/10.1016/j.uclim.2013.07.004

[15] Xie, Q.J. and Zhou, Z.X. (2013) Impact of Urbanization on Urban Heat Island and Effect Based on TM Imagery in Wuhan China. Environmental Engineering and Management Journal, 14, 647-655.

[16] Rosa, D.L. (2013) Accessibility to Greenspace: GIS Based Indicators for Sustainable Planning in a Dense Urban Context. Ecological Indicators, 42, 122-134. www.elsevier.com/locate/ecolind https://doi.org/10.1016/j.ecolind.2013.11.011

[17] Liu, H. and Weng, Q. (2008) Seasonal Variations in the Relationship between LandScape Pattern and Land Surface Temperature in Indianapolis, USA. Environmental Monitoring and Assessment, 1, 199-219. https://doi.org/10.1007/s10661-007-9979-5

[18] Assaye, R., Suryabhagavan, K.V., Balakrishnan, M. and Hameed, S. (2017) Geo Spatial Approach for Urban Green Space and Environmental Quality Assessment: A Case Study in Addis Ababa City. Journal of Geographic Information System, 9, 191 206. https://doi.org/10.4236/igis.2017.92012

[19] Low, N., Gleeson, B., Green, R. and Radovic, D. (2007) The Green City, Sustainable Homes, Sustainable Suburbs. Rutledge, London.

[20] Qian, Y., Zhou, W., Li, W. and Lijian, H. (2015) Understanding the Dynamic of Greenspace in the Urbanized Area of Beijing Based on High Resolution Satellite Images. Urban Forestry \& Urban Greening, 14, 39-47.

https://doi.org/10.1016/j.ufug.2014.11.006

[21] Oke, T.R. (1982) The Energetic Basis of the Urban Heat Island. Quarterly Journal of the Royal Meteorological Society, 108, 1-24. https://doi.org/10.1002/qj.49710845502

[22] Songa, J., Shihong, D., Xin, F. and Luo, G. (2014) The Relationships between Landscape Compositions and Land Surface Temperature: Quantifying Their Resolution Sensitivity with Spatial Regression Models Juer. Landscape and Urban Planning, 132, 145-147. https://doi.org/10.1016/j.landurbplan.2013.11.014

[23] Forman, R.T. (1995) Land Mosaics: The Ecology of Landscape and Regions. Cambridge University Press, New York.

[24] Zhang, Y., Balzter, H., Zou, C., Xu, H. and Tang, F. (2015) Characterizing Bi-Temporal Patterns of Land Surface Temperature Using Landscape Metrics Based on Sub-Pixel Classifications from Land-Sat TM/ETM+ International. Journal of Applied Earth Observation and Geoinformation, 42, 87-96. https://doi.org/10.1016/j.jag.2015.06.007

[25] Zhibin, R. (2014) Estimation of the Relationship between Urban Vegetation Configuration and Land Surface Temperature with Remote Sensing. Journal of the Indian Society of Remote Sensing, 43, 89-100. https://doi.org/10.1007/s12524-014-0373-9

[26] Zhang, X., Zhong, T., Feng, X. and Wang, K. (2009) Estimation of the Relationship between Vegetation Patches and Urban Land Surface Temperature with Remote Sensing. International Journal of Remote Sensing, 30, 2105-2118. https://doi.org/10.1080/01431160802549252

[27] Cao, X., Onishi, A., Chen, J. and Imura, H. (2010) Quantifying the Cool Island Intensity of Urban Parks Using ASTER and IKONOS Data. Landscape and Urban Planning, 96, 224-231. https://doi.org/10.1016/j.landurbplan.2010.03.008

[28] Weng, Q., Liu, H., Liang, B. and Lu, D. (2008) The Spatial Variations of Urban Land Surface Temperatures: Pertinent Factors, Zoning Effect, and Seasonal Variability. IEEE Journal of Selected Topics in Applied Earth Observations \& Remote Sensing, 1,2 . 
[29] Madih, A. (2005) Nishapur and Strategy Development, Physical Geography, Human, Economic and Tourism.

[30] Statistical Center of Iran https://www.amar.org.ir/

[31] State Meteorological Organization http://www.irimo.ir

[32] Ghahreman, N. and Gharekhani, A. (2010) Investigating the Trend of Wind Speed Changes in the Climate of Iran. Iranian Journal of Irrigation and Drainage, 4, 31-43.

[33] Bihamta, M., Mohammad, A.Z. and Chahouki, M.A. (2008) Principles of Statistics in Natural Resources. Tehran University, Tehran.

[34] Chen, G., Yang, P., Kattawar, G.W. and Mishchenko, M.I. (2006) Scattering Phase Functions of Horizontally Oriented Hexagonal Ice Crystals. Journal of Quantitative Spectroscopy and Radiative Transfer, 100, 91-102.

https://doi.org/10.1016/j.jqsrt.2005.11.029

[35] Connors, J.P., Galletti, C.S. and Chow, W.T.L. (2013) Landscape Configuration and Urban Heat Island Effects: Assessing the Relationship between Landscape Characteristics and Land Surface Temperature in Phoenix, Arizona. Landscape Ecology, 28, 271-283. https://doi.org/10.1007/s10980-012-9833-1

[36] Weng, Q., Liu, H. and Lu, D. (2007) Assessing the Effects of Land Use and Land Cover Patterns on Thermal Conditions Using Landscape Metrics in City of Indianapolis, United States. Urban Ecosystems, 10, 203-219. https://doi.org/10.1007/s11252-007-0020-0

[37] Gustafson, E.J. (1998) Minireview: Quantifying Landscape Spatial Pattern: What Is the State of the Art? Ecosystems, 1, 143-156. https://doi.org/10.1007/s100219900011

[38] Neel, M.C. and McGarigal, C.S.A. (2004) Behavior of Class-Level Landscape Metrics across Gradients of Class Aggregation and Area. Landscape Ecology, 19, 435-455. https://doi.org/10.1023/B:LAND.0000030521.19856.cb

[39] Turner, M.G., O’Neill, R.V., Gardner, R.H. and Milne, B.T. (1989) Effects of Changing Spatial Scale on the Analysis of Landscape Pattern. Landscape Ecology, 3, 153 162. https://doi.org/10.1007/BF00131534

[40] Lee, S., Lee, K., Jin, W. and Song, H.K. (2009) Effect of an Urban Park on Air Temperature Differences in a Central Business District Area. Landscape and Ecological Engineering, 5, 183-191. https://doi.org/10.1007/s11355-009-0067-6

[41] Li, H. and Wu, J. (2004) Use and Misuse of Landscape Indices. Landscape Ecology, 19, 389-399. https://doi.org/10.1023/B:LAND.0000030441.15628.d6

[42] Riitters, K.H., O’neill, R., Hunsaker, C., Wickham, J.D., Yankee, D., Timmins, S., Jones, K. and Jackson, B. (1995) A Factor Analysis of Landscape Pattern and Structure Metrics. Landscape Ecology, 10, 23-39. https://doi.org/10.1007/BF00158551

[43] Riva-Murray, K., Riemann, R., Murdoch, P., Fischer, J.M. and Brightbill, R. (2010) Landscape Characteristics Affecting Streams in Urbanizing Regions of the Delaware River Basin (New Jersey, New York, and Pennsylvania, US). Landscape Ecology, 25, 1489-1503. https://doi.org/10.1007/s10980-010-9513-y

[44] McGarigal, K. (2014) Fragstats Help. Department of Environmental Conservation University of Massachusetts Amherst, Amherst. 
Submit or recommend next manuscript to SCIRP and we will provide best service for you:

Accepting pre-submission inquiries through Email, Facebook, LinkedIn, Twitter, etc. A wide selection of journals (inclusive of 9 subjects, more than 200 journals)

Providing 24-hour high-quality service

User-friendly online submission system

Fair and swift peer-review system

Efficient typesetting and proofreading procedure

Display of the result of downloads and visits, as well as the number of cited articles Maximum dissemination of your research work

Submit your manuscript at: http://papersubmission.scirp.org/

Or contact oje@scirp.org 